\title{
Evde Bakım Hemşireliği: Mesleki Yetkinlikler ve Eğitim Standartları
}

\author{
Home Care Nursing: Professional Competencies and Education Standards
}

\author{
Ayşe SEZER*, Hülya DEMİRBAŞ**, Hasibe KADIOĞLU***
}

İletişim: Ayşe Sezer Adres/Adress: Marmara Üniversitesi Sağlık Bilimleri Fakültesi, Hemşirelik Bölümü, Halk Sağlığı Hemşireliği Anabilim Dalı/Üsküdar İstanbul Tel: 0216330 2070/1155 Faks: 02163996242 E mail: ayses_18_9@hotmail.com

$\ddot{O} Z$

Evde bakım hemşireliği, birey ve ailesinin sağllk durumunu etkileyen psikososyal, çevresel, ekonomik ve kültürel faktörleri bir bütün olarak değerlendiren bir hemşirelik disiplinidir. Evde bakım hemşireliği bireyin öz bakım becerilerini geliştirmeyi ve bağımsızlığa hazırlamayı amaçlar. Evde bakım hemşirelerinin hem halk sağlığı hem de ileri düzey klinik yetkinliklere sahip olması gerekir. Ancak ülkemizde evde bakım hemşirelerinin sahip olması gereken yetkinlikler ve eğitim standartları konusu net değildir. Bu makalenin amacı ülkemizde evde bakımda çalışacak hemşirelerinin sahip olması gereken yetkinliklere ve ĕgitim düzeyine açıklık getirmektir.

Anahtar Kelimeler: Evde bakım, hemşirelik, halk sağlı̆̆ı hemşireliği, yetkinlik, sorumluluk.

\section{ABSTRACT}

Home care nursing is nursing discipline which evaluating as a whole the psychosocial, environmental, economic and cultural factors affects individual and family health status. Home care nursing aims to promoting the individual's self-care skills and prepare to independence. Home care nurses are also necessary to have public health and advanced clinical competencies. However, the required competencies and training standards for home care nursing is not clear in our country. The purpose of this article is to clarify must have competencies and educational level of home care nurses in our country.

Key Words: Home care, nursing, public health nursing, competency, responsibility.

\section{GİRIŞ̧}

Son yıllarda tıp ve teknolojideki ilerlemeler, geliştirilen yeni tanı ve tedavi yöntemleri ortalama yaşam süresini arttırmıştır. Bu artış ile yaşlılık ve yaşlanma sürecine bağlı kronik hastalıklar, hastane sonrası bakım hizmetlerine olan talep artmıştır. Bu taleplerin karş1lanmasında farklı bir boyut olarak ortaya çıkan sağlık hizmeti modellerinden en çok kabul göreni evde bakımdır (Erci 2009). Kurum bakımının pahalı olması ve bakıma gereksinim duyan bireyi toplumsal hayattan soyutlaması gibi nedenlerle evde bakım hizmetleri, tüm gelişmiş ve gelişmekte olan ülkelerde hızla kurum bakım sisteminin bir destekleyicisi olarak yerini almaya başlamıştır (Danış 2006; Yılmaz ve ark. 2010).

Günümüzde evde bakımın etkinliğini ve yararlarını ortaya koyan pek çok çalışma bulunmaktadır. Bunlardan; Molassiotis ve ark. (2009) çalışmalarında kemoterapinin yan etkilerinin yönetiminde evde bakım programının

\footnotetext{
**Arş. Gör. Marmara Üniversitesi Sağllk Bilimleri Fakültesi, **Hemşire Üsküdar Toplum Sağlığı Merkezi, ***Doç. Dr. Marmara Üniversitesi Sağllk Bilimleri Fakültesi
}

Yazının gönderilme tarihi: 03.02.2014

Yazının basım için kabul tarihi: 15.03.2015 
standart bakımdan daha etkili olduğunu, Koç ve Eroğlu (2009) doğum sonu altı hafta içinde ev ziyaretiyle verilen hemşirelik bakımı ve eğitimin yeni doğanın kilo alımı üzerine olumlu etkisi olduğunu, Çiftçi ve Yılmaz (2010) Koroner Arter Bypass Greftleme (KABG) ameliyatı geçiren bireylerin \% 77'sinin evde aldıkları bakımdan memnun olduklarını ve ev ortamının rahat olmasından dolayı evde bakımı tercih ettiklerini saptamıştır. Tüm bu çalışmalara bakıldığında sağlık hizmetlerinin sunumunda evde bakıma olan talebin artacağı ve böylece evde bakım hizmetlerin yaygınlaşacağı öngörülebilir.

Sektörler ve disiplinler arası işbirliği gerektiren, sağlık ve sosyal hizmetlerin bütünleştirildiği bütüncül yaklaşımı temel alan evde bakım hizmetlerinin ekip çalışması ve anlayışı içinde sunulması verilen bakımın etkinliği açısından önemlidir. Evde bakım hizmetleri, hastanın evde profesyonel anlamda bakım ve tedavisini içermekte olup, benzersiz ve oldukça karmaşı uygulamaları kapsamaktadır. Bu hizmetlerin sağlanmasında sağl1k ekibinin en önemli üyesi olan evde bakım hemşireleri özellikle bakım verici rolü açısından tedavi ve rehabilitasyonun etkin olmasında, bireyin mevcut sağlık durumunun iyileştirilmesinde önemli rollere sahiptir (Akdemir ve ark. 2011). Bu rolleri yerine getirebilmesi için hemşirelerin hem halk sağlığ hem de ileri düzey klinik yetkinliklere sahip olması gerekir (Duke ve Street 2003). Bu alanda çalışan hemşirelerin, hasta birey ve ailesine kaliteli bir bakım hizmeti sunabilmesi için gelişmiş düzeyde eğitim almaları sağlanarak mesleki bilgi ve becerilerin kazandırılması, sahip olması gereken yetkinlikleri tam anlamıyla bilmeleri ve hızla değişen sağlık bakım sistemine uyum sağlamak için kendilerini sürekli geliştirmeleri önemlidir.

Ülkemizde Evde Bakım Hizmetleri Uygulama Yönetmeliği (2005), Evde Sağlık Hizmetlerinin Uygulama Usul ve Esasları Hakkında Yönerge (2010)'ye göre evde bakım hemşiresinin sorumlulukları: "ilaç uygulama, gözlem ve kayıt, hastalık hakkında birey ve ailesini bilgilendirme ve sağlık eğitimi, alet ve malzemelerin hazır bulundurulması, sorumlu hekimin verdiği diğer görevleri yapma" şeklinde belirlenmiştir (Evde bakım Hizmetleri
Sunumu Hakkında Yönetmelik 2005; Sağlık Bakanlığınca Sunulan Evde Bakım Hizmetlerinin Sunumu Hakkında Yönerge 2010). Hemşirelik Yönetmeliğinde (2011) ise: ev ortamını değerlendirme, bakım destek elemanlarının denetimini yapma, sağlık eğitimi, bireylerin istek ve şikayetlerini dinleme, değerlendirme ve ilgili birimlere yönlendirme şeklinde belirtilmiştir (Hemşirelik Yönetmeliğinde Değişiklik Yapılmasına Dair Yönetmelik 2011). Yasal düzenlemelere bakıldığında evde bakım hemşiresinin sahip olması gereken mesleki yetkinlikler ve standartların belirtilmediği görülmektedir. Bu derleme makalenin amacı ülkemizde evde bakımda çalışacak hemşirelerinin sahip olması gereken yetkinliklere ve eğitim düzeyine açıklık getirmektir. Makalenin evde bakım dersi veren, evde bakım hemşireliği kursları düzenleyen akademisyenler, evde bakımda hizmet sunan kurumlar ve hemşireler için yararlı olacağı düşünülmektedir.

\section{Dünya'da ve Türkiye'de Evde Bakım Hemşireliği ve Ĕgitimi}

Evde bakım hemşireliği; koruyucu, tedavi ve rehabilite edici sağlık bakım hizmetlerinin etkili biçimde sürdürülmesi amacını güden, birey ve ailesine kendi ev ortamlarında sunulan hemşirelik bakım hizmetleridir (Rice 2006a; Sayan 2004). Dünyada evde bakım hizmetlerinin tarihsel gelişimine bakıldığında hemşirelik hizmetleri şeklinde başladığı ve uzun yıllar bu şekilde yürütüldüğü görülmektedir. Evde bakım hizmetleri ilk ziyaretçi hemşire olarak bilinen Florence Nightingale tarafindan 1800'lerde hasta ve yoksul bireylere yap1lan ev ziyaretleri ile başlamıştır (Rice 2006a). Florence Nightingale hasta kişilerin bakımı ile görevlendirilecek olan kadınların özel olarak eğitilmesini önermiş ve eğitilmiş kadınların bölgelerde ev ziyaretleri gerçekleştirmek üzere özel hemşire olarak görevlendirilmeleri ile ilgili bir plan sunmuştur (Lundy, Utterback, Lance, Bloxsom 2009; Y1lmaz ve ark. 2010). Nigtingale'in önerileri üzerine 1862 yılında Liverpool'da evlerde hasta bakımı gerçekleştirecek ziyaretçi hemşire yetiştiren ve 1,5 yıllık eğitim veren ilk hemşire okulu açılmış, bu okuldan mezun olan hemşirelere de "halk sağlı̆̆ hemşiresi” unvanı verilmiştir (Lundy ve ark. 2009). 
Halk sağlı̆̆ hemşireleri, toplumdaki tüm birey ve ailelere ev ziyaretleri, sağlık eğitimleri yaparak sağlığın geliştirilmesi, iyileştirilmesi ve hastalıkların önlenmesini amaçlamaktadır (Friedman 2006; Lundy ve ark. 2009). Bu amaç doğrultusunda evde bakım hemşireliği, yıllardır halk sağlığı hemşireliğinin bir alt bileşeni olarak kabul edilmiş ve günümüzde de bu şekilde kabul görmeye devam etmektedir. Ancak halk sağlı̆g 1 ve evde bakım hemşireliği ortak yönleri olmasına rağmen, her ikisi de kendi içinde birer uzmanlık alanıdır (Friedman 2006). Halk sağlığı hemşireliği toplumdaki tüm bireylerin sağlığının korunması ve geliştirilmesine odaklanırken, evde bakım hemşireliği, hasta bireyin bakımı ve sağlığına yeniden kavuşturulması üzerine odaklanır (Rice 2006b). Dolayısıyla evde bakım hemşiresi ne tam anlamıyla bir halk sağlığı hemşiresidir ne de bir klinik hemşiredir (Duke ve Street 2003). Evde bakım hemşiresi halk sağlığı ve klinik alanların ortak bir sentezini içerir.

Evde bakım hemşirelerinin hizmet alanı hamilelik, bebeklik, yaşlılık gibi özel yaşam dönemleri, kronik hastalıklı (diyabet, hipertansiyon gibi) bireyler, madde bağımlıları, engelliler, terminal dönemdeki hastalar ve günlük yaşam aktivitelerini bağımsız yapamayan bireyleri kapsar (Humphrey ve Nuzzo 2009). Evde bakım kapsamında verilen sağlık hizmetlerinde hemşire hastaneye göre daha bağımsız bir uygulayıcıdır. Bu nedenle evde bakım hemşirelerinin kritik düşünme, özgüven, liderlik özelliği, güçlü iletişim becerisi, yeterli bilgi düzeyi ve karar verme yetisine sahip olmas1 gereklidir (Gönener, Güler, Altay ve Aç1l 2010; Humphrey ve Nuzzo 2009). Evde bakım hemşireleri esnek ve yeterli bir bakım hizmeti sağlamak için halk sağlığı, cerrahi, pediatri, psikiyatri hemşireliği gibi alanların uygulama prensiplerini sentezler (Humphrey ve Nuzzo 2009). Evde kemoterapi, entereostomal terapi, mental sağlık, emzirme danışmanlığı, palyatif bakım, ventilatör kullanımı, ayaktan periton diyalizi gibi farklı alanlarda hizmet verir (Friedman 2006). Tüm bu hizmetlere bakıldığında evde bakım hemşiresinin klinik hemşireden çok daha yetkin ve bilgili olması gerektiği açıkça görülmektedir.
Amerikan Hemşireleri Birliği (ANA) tüm bu alanlarda evde bakım hemşirelerinin yekin olabilmesi için kemoterapi, diyaliz gibi farklı uygulamalara yönelik sertifika programları düzenlemektedir (Rice 2006a). Amerikan Hemşirelik Yetkilendirme Merkezi (American Nurses Credentialing Center) tarafindan genel ve klinik uzman düzeylerinde, evde bakım hemşireleri için geçerli iki tip sertifikasyon ve yeniden sertifika programları düzenlenmektedir. Bu sertifika programlar1 8 hafta süre ile verilmekte ve 5 yılda bir yenilenmesi gerekmektedir. Sertifikayı alabilmek için en az lisans düzeyinde eğitim almış olmak zorunludur. Evde bakım hemşiresi olarak çalışabilmek için sertifika d1şında minimum iki yıllık bir deneyime sahip olma şart1 aranmaktadir (Hume Health Nursing 2014).

Ülkemizde evde bakım hizmetlerine yönelik çıarılan Yönetmeliklerde evde bakım hemşiresinin yetkinlikleri ve eğitimine yönelik standartlar belirtilmemiş, tedaviyi uygulama ve sağlik eğitimi rolleri belirtilmiştir. Ancak evde bakım gibi uzmanlık gerektiren bir alanda çalışacak evde bakım hemşirelerinin sağlığı koruyucu, geliştirici ve rehabilite edici hizmetlerde önemli rol ve sorumlulukları vardır. Bu nedenle evde bakım hizmetlerine yönelik hazırlanan yönetmeliklerin bu doğrultuda hazırlanması gerekmektedir.

Ülkemizde mevcut eğitim sisteminde evde bakım hemşireliği, lisans düzeyindeki hemşirelik okullarında halk sağlığı hemşireliği dersi kapsamında bir ders saati sürecinde verilmekte (Kadığlu, Albayrak ve Esin 2013), bu alanda sadece bir üniversitede uzaktan eğitim metoduyla master programı bulunmaktadır (Ondokuz Mayıs Üniversitesi Bilgi Paketi- Dersler Kataloğu 2014). Lisans düzeyinde ders müfredatları ve evde bakım hemşireliğine yönelik sertifika programları incelendiğinde, evde bakım hizmetleri kapsamında belirli bakım uygulamalarına yer verilmiştir. Bu sınırlı sürede ve kapsamdaki eğitimin, evde bakım hemşireliği gibi uzmanlık gerektiren bir alan için yeterli olmayacaktır.

Ayrica mevcut sistemde evde bakım hizmetlerinde farklı sağlık meslek gruplarından (ebe, hemşire, acil tıp teknisyeni) ve eğitim seviyelerinden (lise, ön li- 
sans, lisans) bireyler çalıştırılmaktadır. Evde Bakım Derneği tarafından evde bakım hemşireliğine yönelik 2006 ve 2007 yıllarında iki defa sertifika programı düzenlenmiştir (Evde Bakım Hemşireliği Sertifika Programı 2006). Farklı hemşirelik fakülteleri tarafından sertifika programları verilmeye devam etmektedir. Ancak sertifika programlarına başvuru için lisans düzeyi eğitim şartı aranmamıştır.

\section{Evde Bakım Hemşiresinin Mesleki Yetkinlikleri}

Evde bakım geleneksel hastane uygulamaları ile karşılaştırıldığında hemşirenin daha fazla otonomiye sahip olduğu görülmektedir. ANA tarafından evde bakım hemşirelerinin yetkinlikleri; "esneklik, yaratıcılık, bireysel ve çevresel farklılıklarda sorunlara yenilikçi yaklaşımlar ve değişen kaynak kullanılabilirliği, bağımsız karar verme" olarak belirtilmiştir (ANA 2009). Evde bakım hemşireleri için Kanada Hemşireler Birliği tarafından üç tip yetkinlik alanı belirtilmektedir. Bu alanlar; temel yetkinlikler, organizasyon yetkinlikleri ve sistem yetkinlikleridir (Underwood ve Henteleff 2010).

\section{Temel Yetkinlikler}

Değerlendirme: Evde bakım hemşiresinin, bireyin günlük yaşam aktivitelerini bağımsız olarak yerine getirebilme düzeyini, yardım gereksinimlerini saptamak ve uygun bakımı planlamak için fiziksel, psikososyal ve çevresel alanlarda yaptı̆̆ 1 değerlendirmedir. $\mathrm{Bu}$ aşamada hemşire, gözlem, dinleme, görüşme, fiziksel değerlendirme bulgularından yararlanır. Değerlendirme aşamasında hemşire, bireyin mevcut sağlik durumu, ihtiyaçları, daha önceki sağlık hikayesi ile ilgili değerlendirme yapar (Licensure of Home Health Care Agencies 2014).

Fiziksel değerlendirme; bireyin günlük yaşam aktivitelerine katılım düzeyi ve aktivitelerini içeren bir değerlendirmedir. Kişinin sağlığı ile ilgili o anki durumunun gözlenmesi ve değerlendirilmesidir. Amaç; ilk verilerin toplanması (veri tabanı oluşturmak), sorunların belirlenmesi (normalden sapmaların belirlenmesi), değişen sağlık durumu ile ilgili olarak tedaviler hakkında klinik karar vermektir.
Psikososyal değerlendirme; birey, ailenin sahip olduğu kültürel-dini özellikleri, kişilerarası ilişkiler ve etkileşimlerin, hastalık durumunun bireyi/aileyi nasıl etkilediğinin değerlendirilmesidir.

Çevre değerlendirmesi; ev ortamı ve güvenlik risklerinin değerlendirilmesini içerir (Mildon ve Underwood 2010).

Bakım Planlama: Evde bakım hemşiresinin, hasta ve ailesine yaptığı ziyaretlerde kapsamlı bir değerlendirme yapması, bakımın planlanmasında önemlidir (ANA 2009; Underwood ve Henteleff 2010). Başarılı bir bakım planında hemşire, birey ve ailesi ile işbirliği yaparak karşılıklı ihtiyaçları belirlemeli, ihtiyaçlara yönelik hemşirelik bakımını planlamalı ve problem çözme yeteneği ile bireyin mevcut sağlık durumunu geliştirmeyi amaçlamalıdır (Underwood ve Henteleff 2010).

Klinik Karar Verme: Evde bakım kapsamında hemşirelik uygulamaları kompleks bir yapıya sahip olduğu için hemşire bağımsız karar verebilmeli ve bireyi bütün olarak değerlendirebilmelidir. Bu açıdan klinik karar verme, evde bakım hemşireliği uygulamalarının merkezi olarak görülmektedir (Gönener ve ark. 2010; OHCA 2011; Rice 2006b; Underwood ve Henteleff 2010). Evde bakım hemşiresi klinik karar verebilmede; kritik ve yaratıcı düşünme yeteneklerine sahip olmalı, sağlık-hastalık durumları gibi yaşam boyu karşılaşılan sorunlar için gerekli sağlık bilgilerini kullanabilmeli ve bağımsız şekilde karar vererek çözüm yolları geliştirebilmelidir (Mildon ve Underwood 2010).

İletișim: Sunulan bakım hizmetinde başarı elde etmek için hemşire, hasta ve aile arasında güvenli, empatik ve sürekli terapötik bir iletişimin kurulması önemlidir (ANA 2009). Etkin bir iletişim, hemşirenin sahip olduğu iletişim bilgisi ve kabiliyetine bağlıdır. Evde bakım hemşiresi etkili dinleme yeteneğini kullanabilmeli, sözlü ve sözsüz iletişim kabiliyetleriyle birey, aile ve diğer bakıma katılan kişilerin duygu ve düşüncelerini anlayabilmelidir.

Kültürel sorumluluk: Bireylerin sağllğa ilişkin inançları, kültürleri, geçmişteki hastalık/sağlık deneyimleri bir bütündür. $\mathrm{Bu}$ bütünlüğün korunması, bireyle- 
rin sağlığını geliştirme ve etkin bir bakım sağlamada önemli bir rol oynar. Sağlık bakım profesyoneli olarak hemşireler, bakım verirken toplumun kültürel yapısını dikkate alarak bakım planlamalıdır (Mildon ve Underwood 2010).

Uygulama becerileri: Evde bakım hemşireleri bireylerin öz bakımını destekleyerek yerine getirmelerini sağlamak amacıyla sahip oldukları özel bilgi ve becerileri ile bir çok spesifik uygulamalarda bulunur. Enjeksiyon, periton diyalizi, parenteral beslenme, kemoterapi, stoma bakımı, yara bakımı, oksijen terapisi, ventilatör kullanımı gibi uygulamalar bu kapsamda sayılabilir. Evde bakım hemşireleri temel pratik uygulamaların yanı sıra hasta birey ve ailesine evde bakım hakkında bilgi ve beceri kazandırmak amacıyla sağlıkhastalık yönetimi ile ilgili eğitim yapmaktan sorumludur (Friedman 2006).

\section{Organizasyon Yetkinlikleri}

Zaman Yönetimi ve Organizasyon Becerileri: Zaman yönetimi ve organizasyon becerisine sahip olma evde bakım hemşirelerinin sorumlulukları arasındadır (ANA 2009). Bu beceriler hemşirenin bakımda verimli olmasını etkilemektedir. Verimlilik, verilen hizmetlerin etkinlik ve yeterliliğinin belirlenmesi ile ortaya çıar. Yeterlilik ise sağlanan hizmetlerden etkin sonuçlar elde edilmesinde hemşirenin ziyaret aktivitelerinde harcadığı zaman olarak düşünülmektedir (Underwood ve Henteleff 2010). Bu nedenle hemşirenin zamanı iyi yönetebilmesi, organizasyon becerisine sahip olmas1 verimli bir bakımın sağlanması ve olumlu klinik sonuçların arttırılması açısından önem taşımaktadır.

Bakım Koordinasyonu: Bakım koordinasyonu; "açıkça belirlenen tedavi planı ve sonuçlarına ulaşmak için multidisipliner bir ekip (doktor, eczac1, evde bakım hemşiresi vb.) tarafından hastanın sağlık durumunu en üst seviyeye çıkarmak" olarak tanımlanmaktadır (CHCA 2005). Hemşirelikte vaka yönetimi olarak da adlandırılan bakım koordinasyonu, hastanın gereksinimlerinin ön planda tutulması esasına dayanır. Bu gereksinimlerin karşılanması için hemşire mevcut top- lumsal kaynakları belirlemeli, hasta birey ve ailesini kaynaklara yönlendirerek kaliteli bir bakım koordinasyonu sağlamalıdır (ANA 2009).

Gelișmiș Teknolojiyi Kullanabilme: Günümüzde gelişen teknolojik sistemlerin her alanda kullanılması, sağlik bakım profesyonellerinin kaliteli ve yeterli bir bakım sağlayabilmeleri için karmaşık teknolojiyi kullanabilmelerini gerekli kılmaktadır (ANA 2009; Brandies ve ark. 2007). Evde bakım hizmetlerinde teknolojik gelişmeler gittikçe artan bir şekilde kullanılmaktadır. Evde bakım hemşiresi, tedavi ve bakım hizmetlerinin sunumu için yüksek teknolojik araç ve cihazların kullanımı hakkında bilgi sahibi olmalı, kullanan kişinin güvenli, doğru kullanımında yardım ve rehberlik etmelidir.

\section{Sistem Yetkinlikleri}

Hasta Savunuculuğu: Hemşirenin sahip olması gereken yetkinlikler arasında olan hasta savunuculuğu rolü önemli bir yere sahiptir (ANA 2009). Bu rolü ile hemşire hastaya ihtiyacı olan bilgiyi verir, gerektiğinde hastanın sözcülügünü yapar, karar vermesini destekler ve kararına saygı duyar (Erci 2009).

Sistem Bilgisi: Hemşire mevcut yasal düzenlemeler, finansal kaynaklar, destek sistemleri hakkında bilgi sahibi olmalı, böylece bakım verdiği bireylere danışmanlık yaparak uygun bir şekilde yönlendirmelidir.

\section{SONUÇ VE ÖNERILER}

Evde bakım hizmeti alan bireylere, kalabalık hastane ortamındaki hizmet sunumundan farklı bir yaklaşımla, güvenli, etkin ve kaliteli bir sağlik hizmeti sunmak için evde bakım hemşirelerinin yetkinlikleri ve eğitim standartları açıkça belirlenmelidir. Bu alanda çalışacak hemşirelerde, en az lisans düzeyinde eğitim alma, sertifika sahibi olma ve klinik deneyim şartı aranmalıdır. Evde bakım hemşireliği lisans, lisansüstü ve sertifikasyon eğitim programları yapılandırılırken evde bakım hemşireliği temel yetkinliklerini esas alacak şekilde düzenleme yapılması, evde bakım hemşirelerinin mesleki yetkinliklerini değerlendiren araştırmalar yapılması önerilir. 


\section{Evde Bakım Hemşireliği: Mesleki Yetkinlikler ve Eğitim Standartları}

\section{KAYNAKLAR}

Akdemir, N. ve ark. (2011). Yatağa bağımlı hastaların evde yaşadıkları sağlık sorunlarına yönelik evde bakım hizmet gereksinimleri. Dicle Tip Dergisi, 38(1): 57-65.

American Nurses Assocation (ANA) (2009). Home health nursing: Scope and standards of practice, http://nursingworld.org/nursingstandards (17.05.2011)

Brandies, G. H ve ark. (2007). Electronic health record implementation in community nursing homes. J Am Med Dir Assoc, 8(1): 31-34. Björnsdóttir, K. (2013). The place of standardisation in home care practice: An ethnographic study. Journal of Clinical Nursing, 23:1411-1420

Canadian Home Care Association (CHCA) (2005). Summary of proceedings from the home care case management invitational roundtable, http://www.hcsc.gc.ca/ hcs-sss/pubs/homedomicile/2005-cas-mgmt-gest/index-eng.php (17.05.2011).

Çiftçi, E. S., Yılmaz, M. (2010). Açık kalp ameliyatı geçirmiş bireylerin evde bakım gereksinimlerinin belirlenmesinde bir model: FSÖ. Türk Göğüs Kalp Damar Cerrahisi Dergisi, 18(3): 183-189.

Danış, M. Z. (2006). Toplum temelli bakım anlayışı ve sosyal hizmetler: Türkiye örneğinde bir bakım modeli önerisi. Türk Geriatri Dergisi, 11(2): 94-105.

Duke, M., Street, A. (2003). Hospital in the home: Constructions of the nursing role a literature rewiev. Journal of Clinical Nursing, 12(6): 852-859.

Erci, B. (Ed.) (2009). Halk Sağlığı Hemşireliği. Fırat Matbaacılık, Ankara.

Evde Bakım Derneği (2010). Ülkemiz için evde bakım modeli oluşturma çalıştayı, Çalıştay Sonuç Raporu, Ankara.

Evde bakım Hizmetleri Sunumu Hakkında Yönetmelik (2005). http://www.saglik.gov.tr/TR/belge/1-570/evde-bakim-hizmetleri sunumuhakkinda\%20yonetmelik.html (20.02.2014).

Evde Bakım Hemşireliği Sertifika Programı. (2006). http://www. evdebakim.org.tr/ Evde-Bakim-Hemsireligi-Sertifika-Programi (17.10.2014).

Friedman, Y. (2006). Mapping the literature of home health nursing. J Med Lib Assoc., 94(2): 49-55.

Gönener, H. D, Güler, Y., Altay, B., Aç11, D. A. (2010). Zihinsel engelli çocuklarda evde bakım hemşireliği yaklaşımı. Gaziantep Tıp Dergisi, 16(2): 57-65.

Hemşirelik Yönetmeliğinde Değişiklik Yapılmasına Dair Yönetmelik (2011). http://www.resmigazete.gov.tr/eskiler/2011/04/20110419-5.htm (17.10.2014).

Humphrey, C. J., Nuzzo, M. P. (2009). Transitioning nurses to home care. Horris, M. D. (Ed.). Handbook of Home Health Care Administration. Jones And Barlett Publisher, India, 515-528.

Home Health Nursing (2014). http://www.nursecredentialing.org/ Certification/ NurseSpecialties/HomeHealth (21.02.2014).

Koç, I. G., Eroğlu, K. (2009). Evde bakım hizmetlerinin doğum sonu erken taburcu edilen yeni doğanlarda görülen komplikasyonlar üzerine etkisi. Hacettepe Üniversitesi Sağllk Bilimleri Fakültesi Hemşirelik Dergisi, 16(1): 25-38.

Kadıŏlu, H., Albayrak, S., Esin, M. N. (2013). Public health nursing education in Turkey: A national survey. International Nursing Review, 60(4): 536-542

Licensure of Home Health Care Agencies (2014). HYPERLINK, http://www.ct.gov/./19-33._home_health.pdf, www. ct. gov//1933.home health. pdf (24.02.2014)

Lundy, K. S., Utterback, K. B., Lance, D. K., Bloxsom, I. P. (2009). Home health and hospice nursing. Lundy, K. S., Janes, S. (Eds.). Community Health Nursing Caring for the Public's Health. 2. basım, Jones and Barletts Publishers, United States, 970-977.

Molassiotis, A. ve ark. (2009). Effectiveness of a home care nursing program in the symptom management of patients with colorectal and breast cancer receiving oral chemotherapy: A randomized, controlled trial. J Clin Oncol., 27(36): 6191-6198.

Meadows, C. A., Procuik, J. (2012). Integrating licensed practical nurses in to home care nursing one health authority's journey. Home Healt Care Nurse, 30(5): 273-279.

Mildon, B., Underwood, J. (Eds.) (2010). Competencies for home health nursing: A literature review. Community Health Nurses of Canada. Public Health Agency of Canada, Toronto, Canada, 7-14. Ondokuz Mayıs Üniversitesi Bilgi Paketi-Dersler Kataloğu (2014). http://ebs.omu.edu.tr/ebs/program.php?dil=tr\&mod=2\&Program=4689 (24.02.2014).

Ontario Home Care Association (OHCA) (2011). Home Care Nursing in Ontario, https://www.homecareontario.ca/ohca-home (20.02.2014).

Rice, R. (2006a). Home care nursing practice: Historical Perspectives and Philosophy of Care, Home Care Nursing Practice Concepts and Application. 4. basım, Mosby, United States.

Rice, R. (2006b). The Rol of The Home Care Nurse Orientation Strategies, Home Care Nursing Practice Concepts and Application. 4. basım, Mosby, United States.

Sayan, A. (2004). Günümüzde evde bakım. Atatürk Üniversitesi Hemşirelik Yüksekokulu Dergisi, 3(7): 91-96.

State of Connecticut Department of Developmental Services (2013). Nursing Standard, http://w8ww.ct.gov/dds/lib/dds/health/ ns_09_1_nursing_process.pdf (22.02.2014).

Sağlık Bakanlığınca Sunulan Evde Bakım Hizmetlerinin Sunumu Hakkında Yönerge (2010). http://www.tkhk.gov.tr/Dosyalar/63df3 17e06a248d7bbd1a74fe876b332.pdf (02.12.2014).

Underwood, J., Henteleff, A. (2010). Development of home health nursing competencies in Canada, http://chnc.ca (07.04.2011).

WHO (2002). Community home based care in resource limited settings: A framework for action, http://www.who.int/chp/knowledge/ publications/comm home based care.pdf (22.02.2014).

Yılmaz, M. ve ark. (2010). Sağlık hizmetinin alternatif bir sunum şekli olarak evde hasta bakımı. İstanbul Tıp Dergisi, 11(3): 125-132. 